\title{
The Politics of Inscription in Modern Chinese Art Craig Clunas
}

'What is the politics of inscription?' is a question posed over twenty years ago by W. J. T Mitchell, and the long history of text-image reciprocity in western picture making continues to be a rich area of research. ${ }^{1}$ This should by rights be a live question in the study of Chinese art too, especially as a particular relationship between text and image has often been seen as one of the distinctive characteristics of Chinese art. Many pre-modern works, among them some of the most famous images in the canon of Chinese painting, carry extensive colophons, inscribed there both by the artist at the time of creation and by subsequent owners and viewers . The 'established answer' as to why Chinese artists inscribed words on their paintings, one which points to the shared technical media of painting and calligraphy in the pre-modern era, and to the resulting conceptual link between these two practices, has more recently been challenged by Zhang Hongxing, who has unpacked the misconceived notion of this as 'some quintessential Chinese trait'. He points out that while it is certainly the case that many early Chinese theorists of word and image shared the view of the ninthcentury writer Zhang Yanyuan (815-875) that, 'Writing and painting have different names but a common being', or would have 
concurred with the words of the fourteenth-century writer Song Lian (1310-1381), who stated 'Thus I say that writing and painting are not different Ways, but are as one in their origin', ${ }^{3}$ this does not make the claim empirically true. Yet it remains a fundamental if widespread misconception that a somehow more 'pictorial' nature of the Chinese writing system explains the close collocation of writing and image in much painting. In truth, only a very small minority of Chinese characters function as iconic signs, i.e. pictures of what they represent in technical semiotic terms. Rather more important in understanding the practices of image-making in China is an acceptance that much of what inscriptions on painting have sought to do within certain kinds of painting in China since at least the fourteenth century is force the viewer to attend to the surfaces, whether silk or paper, on which they are inscribed, and hence act quite deliberately to subvert any risk that the image will be understood as 'realistic', a window onto a world. ${ }^{4}$ The presence of words on the pictorial surface thus plays a major role in preventing the work from displaying any illusionistic pretensions, being at once part of, but equally external to, the image. ${ }^{5}$ Long before Henri Matisse, who famously quipped when challenged over his green flesh that 'Above all, I do not create a woman, I make a picture', 6 the most highly-regarded painters of the Chinese élite canon were similarly aware that the functions of painting were as much about holding attention at a surface as they were on creating an illusion of 
looking at a 'real' scene'. 'Form likeness' (xing si is the Chinese term, meaning something like mimetic accuracy), from at least the eleventh century, came to be increasingly distrusted in the most eloquent of theoretical discussions as the province of the artisan, the craftsman painter, and the viewing choice of the subaltern (women, children, eunuchs), while elite male viewing subjects let their minds rest lightly on higher considerations. It needs to be stressed that by no means all of the practices of Chinese painters over the centuries adhered to this essentially sectarian position, which has come to be known as that of 'literati painting' (wenren hua), but nevertheless few dicta within the canon of Chinese painting theory remain as famous as the bald statement from a poem of Su Shi (1037-1101) that, 'If anyone discusses painting in terms of formal likeness / His understanding is that of a child. ${ }^{7}$

The between words, more specifically poetic words, and images has long been a theme in pre-modern Chinese writing on painting, and remains an active vein of criticism and research in the present day. ${ }^{8}$ There has also been increasing attention in recent years within the study of Chinese art outside China to word and image relations. This is so in the work of Jonathan Chaves on the painter as poet in China (a study in which this experienced literary critic is significantly very sceptical about the literary quality of most of the poems which can be found inscribed on Ming and Qing paintings), or in work on the way in which rhetorical theories of the 
metaphor can help us to understand what is happening in the relationship between poem and image on a famous painting like 'Old Cypress' by the great literati master Wen Zhengming (14701559). ${ }^{9}$ The responses over the centuries to the challenges posed by words and images on a single surface are various, and admit of a wide range of practices, not reducible to one easy formula. However the relationship, on those paintings where it exists at all, always matters. To take just one almost random example, all scholars would accept that, if we wish to understand a work like the delicate painting of orchid and bamboo (plate 1) by the Ming dynasty courtesan painter Ma Shouzhen (1548-1604), we need to understand the interplay of the image with the three poems by the painter herself, her lover the famous literatus Wang Zhideng (15351612), and the work of an enigmatic (or at least less well-known) third figure, Xue Mingyi (active c. 1600). ${ }^{10}$

If we turn abruptly from the pre-modern to the postmodern, putting to one side for the moment the short twentieth century which will be the primary focus of the rest of this paper, it is also observably very much the case that, in the field of contemporary art since the economic reforms of the 1980s, the manipulation of text and of the characters of the Chinese language has been remarked on by critics as a powerful strand of recent artistic practice. It appears in the deconstructive 'washing away' of printed histories of Chinese and Western art by Huang Yong Ping (b.1954), who put Herbert 
Read's ‘A Short History of Modern Painting' and Wang Bomin’s 'History of Chinese Painting' in his washing machine for two minutes in 1987, and boldly titled the resulting unreadable sludge with a very readable title which sits above the wet pile in the finished work; ‘A History of Chinese Painting' and 'A Concise History of Modern Painting’ after Two Minutes in the Washing Machine' (plate 2). Xu Bing (b. 1955), on the other hand, in his unreadable 'Book from the Sky’ of a few years later, laboriously created through the carving of woodblocks in an ancient craft process a huge stock of characters which appear from a distance as though they might be legible, but which prove on closer inspection to be nonsense, no matter how closely you press your nose to the surface. And they are far from being the only artists of the reform era since the 1980s for whom the written Chinese script, globally recognized as a signifier of 'Chineseness' (else why would Chinese restaurants from Oxford to Helsinki and beyond continue to have their names displayed outside in a language most passers-by cannot read?) offered possibilities of appropriation, manipulation and rejection. One scholar has drawn a direct line of connection between the massive encyclopaedic enterprise of the early fifteenthcentury Ming court, the 'Great Canon of the Yongle Reign (Yongle dadian), and the equally massive but mystifying project of $\mathrm{Xu}$ Bing, ${ }^{11}$ while another account of 'Reinventing Books in Contemporary Chinese Art' has quite correctly drawn attention to 
the 'intense negotiation with China's cultural heritage' which is central to the practice of many contemporary artists, as well as reminding us that for the premodern elites who created that heritage, 'Their works often combine images and texts, and are both subjects of viewing and reading' ${ }^{12}$

There is however a potential risk here. This prominence of the word has often seemed to be central to understandings of Chinese art which see it as essentially and totally different, not from 'Western art', but more radically from 'art' itself. In the history of art, just as much as in the case of politics or economics, it is, to quote Eric Hayot, 'China, more than any other place, that has served as the 'other' for the modern West's stories about itself, from Smith and Malthus to Marx and Weber [...]. ${ }^{13}$ The story of 'Chinese art', as composed outside China, is one which has for centuries stressed points of difference and downplayed points of similarity. Hayot is quite rightly skeptical of all and every reductive account of a distinctive Chinese aesthetic as preoccupied (over centuries) with 'the line' (or any other equally reductive single feature). ${ }^{14}$ The place of the word in the image has perhaps too often been just such a reductive single feature.

The prominence of textual inscription in 'traditional' Chinese painting and its salience in the art of the last thirty years can perhaps too easily be smoothed into a semblance of continuity. But what of this relationship in the intervening years between these two 
high points, the decades of a 'short twentieth century' from the fall of the Chinese imperial system, and its replacement by a Republic in 1911, through the years of the People's Republic after 1949 to the death of Mao Zedong in 1976? Neither premodern nor postmodern, these were the years when Chinese artists produced a diverse range of solutions to the problem of 'modernity' in art, and in particular to the problem of producing work which could be seen as both 'modern' and 'Chinese'. The fact that artistic 'modernity' in these decades, at least as expressed in the views of many influential western critics from Roger Fry (1866-1934) to Clement Greenberg (1909-1994), required a rigorous separation of word and image, put particular difficulties in the way of Chinese painters, whether those trained in the European academy like Xu Beihong (1895-1953), or those who committed themselves to reinvigorating the practice of what was now being called 'national painting' (guohua), such as Pan Tianshou (1897-1971). This put artists who wished to use inscription into a very particular tight spot, in the larger context of debates about what it meant for a painting to be both 'modern' and yet still 'Chinese', as part of the art able to play its full part in the national project of revival and renaissance. The work of a painter like Chen Shizeng (1876-1923) might have ticked the second box, but it failed to meet the first criterion. It failed despite his ingenious argument that his form of art was indeed modern, and modern by virtue of the fact that (like the Cubism, Futurism, Expressionism 
with which this well-read and cosmopolitan intellectual was perfectly familiar), it deliberately eschewed the attempt to capture the mimetic reality of the observed world in favour of an engagement with the world as refracted through an artist's subjectivity. ${ }^{15}$ A work like Chen’s hanging scroll 'Viewing Paintings' of 1917, despite the novelty of its subject matter, which shows the first paying art exhibition staged in Beijing in that year, despite the novelty of its style, and despite the cosmopolitan newness of the crowd of both European and Chinese viewers it portrays, could not be seen as a 'modern' painting. ${ }^{16}$ It is hard not to see its prominent inscription as part of what disqualified it from 'modernity' in the eyes of foreign viewers, and made his 'national painting' (the literal meaning of guohua, the neologism in use from the 1920s) into 'traditional Chinese painting', as this term is now regularly translated into English by both foreign and Chinese commentators, stripping away its pretensions to a distinctive Chinese modernity. This is not to argue that the presence of text of itself makes a work 'Chinese' through the expression of some timeless (and stable) cultural essence, while the category 'modern' allows of more complex and ambiguous definitions; but it is to argue that perceptions of an essence of 'Chineseness' (not all of them created within the country itself) did form part of the way in which lengthy inscriptions on paintings were received in the interwar years. 
If Chen Shizeng's work by virtue of its 'traditional' qualities could not be 'modern' (since the pair are mutually constitutive and hence each excludes the other), then other works contemporary with it like the 'Self-Portrait' of 1911 (plate 3) by Li Shutong (18801942), or like the cityscape of 1922, showing Qianmen in Beijing (plate 4) by Liu Haisu (1896-1994), disqualified themselves from full authenticity on the other count, by not being sufficiently 'Chinese'. ${ }^{17}$ Liu Haisu's painting is dominated by two structures, by the huge Front Gate of Beijing, built originally in the Ming dynasty, but also by the domed and distinctly modern concrete roof of Beijing's principal railway station to its right. Text is conspicuously absent from both of these works, or at least the only writing they are allowed to contain (since they self-consciously wish to be 'modern' paintings) is the minimal signature of the artist. In the case of Li's self-portrait an imitation of a seal in oil paint is present at upper right, but Liu Haisu's work is signed prominently in one horizontal line, also in the upper right corner, and carries his personal name in two forms, with the Chinese characters Haisu (read here in the 'western' manner from left to right) separated by the date '1922' from the initials 'H. S.' in the Latin alphabet. The same practice can be observed in the bottom right hand corner of the painting 'After the Bath’ (plate 5), by Fang Junbi (1898-1986), which is signed both in the Chinese characters of her name and the romanization of it she used through her life, Fan Tchunpi. Here, in marked contrast 
to the practice of Liu Haisu a year earlier, the Latin script runs left to right, while the three Chinese characters form a vertical line, read from top to bottom. The problem of how to sign work was clearly a vexed one for the artists of the Republican era, who chose a variety of solutions, with no single practice emerging as dominant. In one 'Nude’ from 1930 by Guan Liang (1901-1986) the signature is executed in the Latin alphabet alone, while in another portrait of the artist Guan Zilan (1903-1986) painted in the very same year, in the same medium of oil paint and in the same broad style, the artist Chen Baoyi (1893-1945) chooses to render both his own name and the date entirely in Chinese characters. ${ }^{18}$ This was also the practice of Xu Beihong, the most prominent (and in his own mind the most significant) of the realist painters of early twentieth-century China; his exquisite academic figure studies, which won him prizes at the École des Beaux Arts in Paris in the 1920s, are often signed in pencil entirely in Chinese characters, plus the red impressed seal, as if he needed to affirm an identity, that of the modern, Chinese artist, which he could not trust the images themselves to convey. ${ }^{19}$ While his work in the guohua style continued to make lavish and prominent use of techniques of inscription, his oil paintings from the same period efface text almost totally, and are without very prominent signatures in either script, almost as if he feared that to sign in one script or another or both would subvert his project (a common project, but one then with many solutions) of an art that 
did not have to come down on one side or the other of the vicious conundrum, 'either Chinese or modern'. ${ }^{20}$ Xu Beihong may well have preferred to resist this binary, but the discursive fields within which painting was discussed both in China and beyond it made it inescapable. The starkness of the choice is shown in the definitions of what could and could not be 'Chinese painting' employed in the several exhibitions shown in Europe in the 1930s. In his introduction to the exhibition of 'Chinesische Malerei der Gegenwart' held at the Prussian Academy of Arts in Berlin in 1934, the sinologist and curator William Cohn (1880-1961) asserted that, 'Just as it remains faithful to the traditional repertoire of motifs, recent Chinese painting remains true to traditional painting techniques'. His conclusion however contains the admission: 'Equally popular in China is a school of painting which employs the same techniques and subjects as Western oil painting, but this does not concern us here, since it was not included in the exhibition, and rightly so'. ${ }^{21}$ However popular, work produced in China by Chinese artists cannot be 'Chinese painting' by virtue of those facts alone, but must 'rightly' be excluded from the category.

The tensions this situation produced are palpable in the works of art themselves. Some of the most interesting paintings of early twentieth-century China show what might be seen as a disjunction between the pictorial planes of foreground and background, almost as if they have been originally conceived as parts of two different 
works. $^{22}$ This effect can be seen in 'Viewing Paintings' of 1917 by Chen Shizeng, where the background is formed by two metapaintings - the term is used here in the narrow sense of images within the image - executed in long-established forms of brushstroke, while the figures in the foreground are modelled in washes Chen had probably first seen in Japanese forms of sketching, themselves understood as appropriations of a foreign manner. ${ }^{23}$ It can perhaps be seen too in Fang’s ‘After the Bath’ (plate 5), where the foreground figure expresses the training in life-drawing the artist had received at the École Normale Superieure des Beaux Arts, under the tuition of Ferdinand Humbert (1842-1934), while a background window of bamboo leaves, each leaf a brushstroke in the established manner, creates a geographical specific setting for the otherwise racially indefinite nude body. ${ }^{24}$ The double signature is here just another reminder of the dual identity - Parisian and Shanghainese, Chinese and Western - of the artist herself. It is hard not to see these internal struggles in certain pictures as the visual image of the violently polemical context of debate around painting which marked the cultural life of the less than forty-year period between the demise of the Qing empire in 1912 and the Communist Party victory in China's prolonged civil war, leading in the end to the 'Liberation' of 1949, years of traumatic war and revolution. ${ }^{25}$ In this debate, the status of 'realism' was often central, considered by some as synonymous with 'Western' (and hence 'modern' art), by 
others as an outmoded stage which China could bypass in the search for an indigenous modernity based on subjective expression, and by holders of a third position as a lost part of China’s own early artistic heritage which simply needed to be revived. ${ }^{26}$ But perhaps even more than stylistic ambiguities, the practice of the double signature, in Chinese characters and in Latin alphabet, is yet another powerful acting out on the picture's surface of the tensions and conflicts which afflicted the pictorial field during these years.

After 1949, the Communist Party insistence on a clarity and immediacy of meaning in any image disseminated to 'The People', produced further pressures with which artists and their audiences had to engage. By now, ambiguity and uncertainty were to be expunged altogether in preference to clarity and directness of message. Even though Mao’s theoretically prescriptive 'Talks at the Yan'an Forum on Literature and Art' were themselves notoriously vague, and even though in practice debate continued to exist behind the façade of unambiguous party policy, artists who were thought to favour lack of clarity got into trouble, while paintings which would appear to be of impeccably correct political stance could in certain contexts land their makers in highly dangerous political circumstances. ${ }^{27}$ Nevertheless, the answer to Mitchell’s question, 'What is the politics of inscription?' in the People's Republic between 1949 and 1966 is that initially it largely continued the patterns set down in the earlier Republican era, but with the single 
though highly significant difference that the 'double signing' in two scripts almost entirely vanishes from the artistic scene. In the early 1950s, forms of private and personal viewing of artworks still existed, and the forms of elite sociability which had prevailed between gentlemen for centuries retained a certain degree of purchase. A fan leaf, dated 1953 and painted with plum blossoms (plate 6), is by the actor Mei Lanfang (1894-1961), the leading exponent of 'Peking opera' in the twentieth century (and last great male actor of female roles), admired by Berthold Brecht (18981956) and Charlie Chaplin (1889-1977) alike, and another part of the cultural heritage carefully curated by Mao Zedong's New China. ${ }^{28}$ It perhaps looks at first glance like the kind of conventional image that could have been painted any time in the Ming or Qing periods (Mei Lanfang was not particularly renowned as a painter), and the subject of plum blossoms is hardly an unconventional one. However the image is pointedly dedicated to 'Comrade Yuanying' (Yuanying tongzhi), using the appellation of the new egalitarian ethos of the socialist era.

An oil portrait (plate 7) of the ninety-year old guohua artist Qi Baishi (1864-1957) by Wu Zuoren (1908-1997), who had studied before 1949 in Paris and had at one point cultivated a more polemically modernist style, was painted in 1954, in an academic oil painting style, the style which was rapidly becoming the official descriptive mode of the party-state in China. ${ }^{29}$ It is signed by $\mathrm{Wu}$ in 
the upper right corner in Chinese characters alone, though the artist makes the choice to render the date in Arabic numerals, so perhaps a bit of the old duality is hinted at. This image of the most distinguished practitioner of what was by the 1950s universally understood as 'traditional Chinese painting', is also perhaps a way of saying that this tradition is now enfolded within the modernity which the party and the state embody. There is here perhaps a kind of stylistic internal orientalism, in which guohua, 'Chinese painting' (at least in its mainstream manifestations), can be spoken about, spoken for, but is less able to speak for itself. By painting its most distinguished living painter in an utterly different manner to that which he deployed himself, it is as if an argument is being made, a reminder is being offered that 'Chinese painting' will not be the way in which the party, the state and its leaders are shown to the people; another mode of art will be employed in that task.

The instigation by Mao Zedong of the Great Proletarian Cultural Revolution (Wuchanjieji wenhua da geming) in 1966 meant the temporary abeyance in China of most kinds of images without words on them or in close association with them, and the distinctive posters and graphics of the late 1960s are still some of the most immediately recognisable visual images from China’s recent past. ${ }^{30}$ In her extensive argument for taking seriously the culture of the Cultural Revolution as 'lived experience', Barbara Mittler has argued that this period represents 'not the exception but 
the norm in cultural production in modern and revolutionary China', stressing its continuities rather than discontinuities with earlier periods of both Nationalist and Communist Party rule. ${ }^{31}$ But that definitely does not mean that it is a homogeneous era in itself. Probably no period of Chinese art (until its recent re-awakening by the magic kiss of a hyperactive art market) has been less highly regarded than that of what would now be categorized as the 'late Cultural Revolution period', the early to mid-1970s years of stasis, tedium and ongoing repression which succeeded the chaotic and violent initial years of the Cultural Revolution, a phase which was largely over by 1970, if not even by $1968 .{ }^{32}$ Official Chinese Communist Party discourse today, and most standard textbooks of modern Chinese history, are content to lump together the decade from 1966 to 1976, when the death of Mao provided the occasion for the major change of policy following the coup d'état by that faction of the Party whose heirs continue to rule China today, and to see this decade as the 'Ten Years of Chaos' (Shinian dongluan). But in fact this period contains within it a considerable degree of variety, and was experienced as one of great change by those who lived through it. By 1974, for example, the famous 'Little Red Book' of Mao's quotations was absolutely invisible in Chinese daily life, as were badges bearing the image of Chairman Mao. At this point, official discourse within China had it that the Cultural Revolution had been 'victoriously concluded', and that the 
‘Campaign to Criticize Lin Biao and Confucius’ (Pi Lin pi Kong yundong), which yoked together as demonized enemies the ancient sage and the now-disgraced (and mysteriously dead) former designated successor to the Great Helmsman, the military commander Lin Biao (1907-1971), was a completely new stage of the revolutionary struggle. ${ }^{33}$

Much of the official art of the early to mid-1970s lacks the urgency and manic vitality of its late 1960s predecessors. It is an art under very tight central control. Much of it could be (has been) called Bad Art. But bad art, like bad objects, can be instructive too, and drawing on the work of the psychoanalyst Melanie Klein W.J.T. Mitchell has proposed that we pay attention to what, 'we might call bad objects, or objects of the Other'. He goes on to stress that, 'Bad objects, then, are not simply bad in some straightforwardly moral sense. They are objects of ambivalence and anxiety that can be associated with fascination as easily as with aversion. ${ }^{34}$ One of the very distinctive features of this art, as has already been observed by Francesca Dal Lago, is that much of it contains writing within it, not writing on (as with the 'traditional' practices of inscription, many of them related to the assertion of individual artistic agency), but writing in the pictorial field. ${ }^{35}$ So for example in a picture from 1975 entitled, 'Taking to the Court' (plate 8), by Nan Yunsheng (b.1944) and Wan Guixiang (b. 1944), and which shows a basketball match taking place in a rural setting between married and 
unmarried women of the village, the slogan painted on a wall in the background is easily legible as: 'Dig caves deep, store up grain, do not strive for hegemony' (Shen wa dong, guang ji liang, bu cheng ba). ${ }^{36}$ This is one of Chairman Mao's more gnomic pronouncements, promulgated in December 1972 in the party organ 'Red Flag', but often seen in the early 1970s in rural settings. ${ }^{37}$ It is a statement with an author (Chairman Mao himself, as viewers would be well aware), but that authorship is not ascribed here. The blackboard in the lower right of the picture carries the chalk slogan 'Friendship First, Competition Second' (Youyi diyi bisai di’er), which was the approved rubric under which all sporting endeavours were to be carried out. Variously ascribed to Mao and to Premier Zhou Enlai (1898-1976), ${ }^{38}$ it too appears here as an exhortation without an individual author. Beneath the slogan are the names of the two teams, 'Red Wives' (Hong dasao) and 'Iron Girls' (Tie guniang), and in front of the blackboard a member of each team puts the ideal comradely sporting relationship into practice by swapping tips on effective strategems. There are other clear and fixed iconographic signs of identity here, like the head towels which identify married women, and the red sweatshirts of the 'iron girls', named for their heroic labours in socialist construction. We are regionally located too, in that the knotted head towel of the older man to the left situates the contest in an identifiable region of north China, in Shaanxi province, site of the revolutionary cradle of 
Yan'an and of the model agricultural commune of Dazhai, from which all peasants were to learn. ${ }^{39}$

This picture, like several others discussed below (see plate 9 and plate 10) is defined as a nianhua, a term which literally means 'New-Year Painting (or Picture)', and which has long signified a mass-produced image of wide distribution; the name refers to the practice of replacing old images (often in past centuries images of apotropaic deities) with new ones at the Lunar or Chinese New Year. As James Flath has shown, from early in the twentieth century nianhua were one vehicle for the dissemination throughout rural China of images of modernity. ${ }^{40}$ The form was seized on by the Communist Party after Liberation, modified under the label xin nianhua ('new nianhua'), and formed one of the key cultural tools in bringing Party policies to a wide audience. ${ }^{41}$ 'New-Year Pictures' are hard to distinguish from the wider category of posters or of xuanchuanhua 'propaganda pictures', but it was the practice by the 1970s for the state to exhibit and publish an approved selection; it is just such a selection which provides the examples discussed here. They exist now only in the form of glossy reproductions, as the 'originals' may well no longer survive, and although they were exhibited at least once at the time it is primarily as reproductions in book or individual poster form that they were viewed. Note that by 1975 one change from the 'high' Cultural Revolution era of the late 1960s lies in the fact that individual artists (or sometimes more than 
one artist) are now credited with the authorship of the works; they are not signed within the pictorial field itself, but are credited on the blank 'frame' which accompanies the images in publication, as well as being listed in its table of contents. In immediately earlier years even the most widely distributed images, such as the famous 1967 oil painting ‘Chairman Mao Goes to Anyuan’ by Liu Chunhua (b. 1944), were initially presented to the public as anonymous, collective endeavours. ${ }^{42}$ However this willingness to allow the attribution of works to individual creators, and thus begin the rehabilitation of the entire category, should not be taken as evidence in the mid-1970s of a wider cultural 'thaw'. If anything, prescription around images grew even tighter than it had been in the Cultural Revolution's earlier and more chaotic phase.

Issues of identity and language, with a tight, unambiguous bond between signifier and signified, are very clear in another painting from the same year of 1975, entitled 'The Bright Red Star Lights up Ten Thousand Generations’ (plate 9) by Pan Dingding (b.1936). ${ }^{43}$ 'Bright Red Star' (Shanshan de hongxing) was the hit movie of 1975 in China, with its tale of the heroic little boy Pan Dongzi, orphaned in the 1930s after the brutal murder of his parents by Nationalist forces, who joins the Red Army as a child soldier. ${ }^{44}$ Its theme song was on the radio constantly, and was the material for countless professional and amateur performances, one of which is taking place in the picture before us. Viewers would be likely to 
recognize the boy singer as impersonating Pan Dongzi himself, but just in case the message is rammed home in both pictorial and textual forms. The boy actor is on the front cover of 'People's Pictorial' (Renmin huabao), the title of which is legible at bottom centre. Two girls at bottom left study the lyrics of 'Song of the Red Star', presumably all joining in the performance which the central boy leads so lustily. And behind him on a blackboard we get the message all good children need to take to heart, 'Learn from Pan Dongzi'. We see it in two scripts, in Chinese characters but also in the Latin alphabet used in China to render several of the Turkic languages of China's far west. This is writing in Kazakh, and we are in the Tianshan mountains of the Xinjiang Uighur Autonomous Region, but this identification would be possible without the writing, since many of the figures in the painting, adults and children alike, are dressed in the distinctive clothing of the Kazakhs, or at least in the tightly codified version of Kazakh dress which is the visual signifier of their status as an official 'national minority' of the People’s Republic of China. Others are Uighurs and Kirghiz, equally clearly identified by hats and clothes. Semiotic certainty is palpable here.

This interpenetration of text and image reaches some sort of apogee, indeed becomes almost frenzied, in a work entitled 'Report on Graduation’ (plate 10), by Huang Gu (b. 1939). ${ }^{45}$ The iconographical density and fixity of this picture is as intense as any 
medieval European saint's image. We see a gathering in a rural setting, where a standing young woman reads from a script to an audience of older seated men. To the left a group of middle-school students (those graduating from the highest level of school education in China) are identifiable by their clothing, while the presence of members of the national minorities in distinctively ethnic dress tells us that we are somewhere in the relatively remote south-west of China (they are significantly placed at either edge of the composition, to underscore their marginality). In the central background of the scene the red neckerchiefs of 'Little Red Soldiers' (Hong xiao bing) identify younger primary-school pupils, who hang eagerly on the words of their elders and role models. Minute differences of dress are enough to pick out a commune leader (peasant jacket), a party secretary (notebook and pen) and a school teacher (the glasses mark out the intellectual). But what is immediately striking in this image is the overwhelming presence of text, with at least a dozen readable pieces of Chinese embedded within the image; Dal Lago has called these 'visual metatexts' ${ }^{46}$ The whole scene is presided over at the top edge by the common slogan of the day written in white on red, 'Education at the Service of Proletarian Politics', while a banner with black characters on white in the top left corner proclaims the setting to be a 'Report Exhibition on Running the Middle School with the Doors Open’. 'Running the School with the Doors Open' (kaimen banxue) was 
the widely-disseminated 1970s slogan for the idea that education should not be divorced from society, but that pupils should for example take part in productive labour as part of their education, as well as being exposed to the teaching of members of society other than just trained professional teachers. ${ }^{47}$ On the table in front of the girl, ready for signature by herself and perhaps her eager classmates, lies a document entitled 'Declaration of Determination to Return to the Countryside in the Service of Agriculture', a resolution that the higher education to which she is presumably headed will not be sought by her and her classmates as a path of social advancement and a move away from the countryside, but as a source of technical knowledge that will be brought back to the rural setting, where the model subject will 'Learn from the workers, learn from the peasants, learn from the soldiers', as the document on the table in front of the party secretary proclaims. The young woman holds in her hand a 'Report on Line Education', that is to say on the Manichaean struggle between the correct revolutionary line of action and the evil revisionist one, which provided the master-narrative of Maoist politics at this period. Behind her is the visual evidence of an educational investigation into the class history of the village, displaying the broken bowl which signifies the impoverished life of poor peasants prior to the Liberation of 1949, on top of a document titled 'Class [as in 'social class'] Investigation', while the slogan on a straw hat commits its wearer to the 'Arduous Struggle' which is 
the means by which the return of such bad old days can be prevented. This by no means fully exhausts the legible text which exists within the picture, as we see labels and banners signalling the presence of 'Irrigation Shock Troops' (the red banner on the lefthad wall), as well as identifying the very type of sugar cane grown on the 'Self-Reliance School-managed Allotment' (centre-back), and the kind of oil press manufactured by the 'Upper Second Agricultural Machinery Class’ (bottom right).

On one level this is an extremely realistic image. Historians of everyday Chinese material culture who in the future wish to know what plastic shoes looked like in the 1970s, what thermos flasks and glasses for tea looked like, how little girls did their hair or what kind of blouses they wore, will find this and images like it a rich source of perfectly accurate (if cleaned-up) information. Similarly historians of language will find themselves accurately guided as to what sorts of public text were present at this era. But on another level of course this is a political fantasy, one which would have been explicitly called propaganda (xuanchuan) then in China and would be called propaganda now outside it with a much less neutral sense, rather in the sense that propaganda is necessarily a lie. That this is an ideologically saturated image we can have no doubt. Like the other examples in the 1975 nianhua collection it interpellates its viewers, hailing us as audience so that we recognize ourselves as the kinds of subjects the party-state wishes to make for itself (and 
indeed this effect is augmented by the composition, which implies a circle of chairs completed by us the viewers, who are thus also present at this scene of socialist dedication, if slightly held at bay by the farm machinery in the foreground). Like the advertising images which within a few short years succeeded it in China, this is an image of life as it should be, one which accentuates the positive to an almost demented degree, such that it is impossible to look at such things now without seeing them as revolutionary kitsch. The falsity which makes them 'Bad Objects' in the moral sense is probably most visible embedded in the manic grins of pleasure which alike wreath the faces of basketball players, of singing Kazakh children, of graduating high school students and their audiences. In the latter case the pleasure strikes a particularly implausible note in that the wider context of this image is one of the most unpopular policies of the Maoist era, that of sending 'educated youth' (zhishi qingnian, often abbreviated to zhiqing) from the cities to the countryside, with no immediate hope of return. ${ }^{48}$ Although the girl in the picture affirming her determination to return to the countryside is local to the village, and hence is not one of the urban middle-school graduates being sent there for the first time, the image's relevance to the policy of 'educated youth up to the mountains and down to the countryside' (zhishi qingnian shangshan xiaxiang) is inescapable in the context of 1975 . While foreign students at Beijing Languages Institute were playing for a 
few days at being peasants, their younger Chinese contemporaries in their millions were facing the prospect of that uprooting for real, of being thrust into an environment with much lower living standards, at the mercy of arbitrary local power-holders, where sexual assault and violence were ever-present threats. This image is therefore arguably an image of trauma, or more precisely an image which masks a trauma, one which like so many in modern Chinese history is never addressed at the level of the 'public text', or addressed only somewhat obliquely in contemporary life and culture, through for example the now-extensive body of fiction which deals with the zhiqing experience. ${ }^{49}$

The ubiquitous presence of text, it might be argued plays a major role in the attempt to repress that trauma. The Swedish sinologist Michael Schoenhals has demonstrated the importance in China in the 1960s and 1970s of what were known as hongtou wenjian, literally 'red-top documents', circulars from the central propaganda organs of the party which defined the precise language, the formulae or in Chinese tifa, in which certain topics were to be discussed. ${ }^{50}$ It was the institution of the hongtou wenjian which ensured that any sporting contest would be framed by the formula, 'Friendship First, Competition Second', or which decreed exactly which of Mao's pronouncements were fit to be painted on walls (and on which kind of walls). It is worth pausing to remind ourselves that the kind of saturation of image with readable text 
which we see in 'Report on Graduation' is not simply a factor common to 'totalitarian art', the category into which the critic Igor Golomstok (b.1929) has subsumed equally Soviet Socialist Realism, the art of National Socialism in Germany, and the imagery of Mao's China, seeing them as a 'total realism [...] which is in essence identical' ${ }^{51}$ Painted well over a decade after the decisive rift with the USSR, 'Report on Graduation' is not some simple translation of a Soviet model to Chinese soil, indeed it is hard to think of anything like it in in the official socialist realist art of the USSR. Nor can we see it as a continuation of the inscriptional practices of some timeless and essentialized 'Chinese art'. The inscription on Mei Lanfang's fan (plate 6), like the countless earlier inscriptions which it prolongs and reproduces, acts to remind us that we are looking at a product of human agency, to draw attention to the fictive qualities of the picture of blossoms we are looking at. The numerous inscriptions inside the image, which we might call 'metadocuments' (Dal Lago prefers the term 'metatexts'), serve a precisely opposite purpose. In one way they are like the countless details in the nineteenth century novel or the archaeologically accurate props in the academic painting of the same era, in the work of someone like Lawrence Alma-Tadema (1836-1912); that is to say they are part of a Barthesian 'reality effect'. ${ }^{52}$ But why should that reality effect be achieved so insistently here through words incorporated within the 
picture as well as through the pictured details of shoes and notebooks and thermos flasks?

Here the Chinese use of text within images is better understood in relation to specific histories and not as part of a cultural stereotype. The answer to the question above, it might be suggested, lies in the powers of exact and not merely proximate repetition intrinsic to language and script, and the anxiety felt within the Party about the potential risks of messages conveyed by images alone, however many times those images were reproduced. We remain much less well informed about how images, as opposed to texts, were approved for dissemination in China after 1949, but it seems clear from the nature of the medium that it is easier for the state to prescribe verbal formulae than it is to prescribe in advance how pictures will look (as opposed to proscribing them after their creation if they fell short of the desired effect). ${ }^{53}$ What Rainer Gries has termed 'propagemes' sit more easily in the realm of the verbal than the visual. ${ }^{54}$ The precision with which certain things could only be spoken about in certain ways had in China by the early 1970s reached an unprecedented pitch. Travelling in China in April to May 1974, just as the enigmatic but insistent 'Campaign to Criticize Lin Biao and Confucius' was reaching its first wave of intensity, the French philosopher, literary critic, coiner in 1968 of the notion of 'reality effect' and unconventional gauchiste Roland Barthes (19151980) was struck by the prevalence of what he called in his diary 
'bricks' (briques). 'Bricks’ were for Barthes the 'ritualistic phraseology', the combined and recombined verbal formulae which formed the matter of the endless jieshao or 'introductions' which all visitors to China at that period sat through at communes, kindergartens, tractor factories, ancient historic sites and brand new irrigation canals. Listening to one such pile of bricks from a professor at Beijing University, he noted in his diary: 'The unhappy, and naïve, man does not suspect that we have heard his speech in its entirety, ten times already. Or is this of no importance to him? Change of value: originality is no longer a value, repetition is not a drawback, 55

On the Air France flight home Barthes noted gloomily the centrality of that repetition to the Maoist project, expressing his disillusion with the sentence, 'So it would be necessary to pay for the Revolution with everything I love: 'free' discourse exempt from all repetition, and immorality'. ${ }^{56}$ The central place of insistent repetition in Cultural Revolution art is clear, but what is less clear is the meaning of that repetition, which is surely something other than yet another demonstration of the truism that Walter Benjamin somehow 'got it wrong' about the aura-withering effects of reproduction. ${ }^{57}$ Barthes undoubtedly knew what repetition meant, or at least knew what it meant for the version of Freudian theory espoused by his great psychoanalytic contemporary, Jacques Lacan (1901-1981), for whom 'the real' was to be defined in terms of 
trauma, and for whom (in the interpretation of Hal Foster):

'Repetition serves to screen the real understood as traumatic. But this very need points to the real, and at this point the real ruptures the screen of repetition'. 'I repeat because I repress', is one of the most fundamental of Freudian mantras, used by Foster to interpret the work of an artist whose fame was at its peak on the other side of the globe in the very years of the Cultural Revolution, Andy Warhol (1928-1987). For Warhol, who famously said, 'I like things to be exactly the same over and over again', repetition is 'both a draining of significance and a defending against affect'. Warhol's images of car crashes and electric chairs in Foster's understanding produce traumatic effects as well as reproducing them; they are 'a warding away of traumatic significance and an opening out to it, a defending against traumatic affect and a producing of it ${ }^{58}$ There is, however, another way of dealing with the real, and this is through the practice of what Foster goes on to call 'superrealism', 'a subterfuge against the real, an art pledged not only to pacify the real but to seal it behind surfaces, to embalm it in appearances'. He writes of three ways in which superrealism attempts this sealing, the second being 'to reproduce apparent reality as a fluid surface [...] [which] derealizes the real with simulacral effects', effects which Foster relates to the pop paintings of James Rosenquist (b. 1933), Audrey Flack (b. 1931) or Don Eddy (b. 1944). ${ }^{59}$ Is this not what we see in a work like ‘Report on Graduation’ (plate 10), its shiny surfaces 
(and remember that 'red', 'bright', 'shining' or hong, guang, liang were the three highest desiderata of 'revolutionary romanticism' $)^{60}$ acting to seal behind surfaces, to embalm in appearances, the social stress and trauma of the highly unpopular policy of forced migration of urban youth to the countryside, only one of the many unspoken traumas of the late Maoist era? In combining both repetition, through the insistent use of 'bricks' of language, and superrealism; through its meticulous depiction of that language alongside the shoes and thermos flasks; a work like 'Report on Graduation' comes to a new formula for the repression of the real, one which approached the problem from both sides, so to speak, and which reflected the intensity of that trauma, as the 'Ten Years of Chaos’ meandered towards their end. The issue of realism's relationship to the 'politics of inscription' thus opens up as an area of potential enquiry in China's modern art over a longer time period, and it might be profitable to revisit something like the varied inscriptional practices of the 1920s in this light. If we embrace Barbara Mittler's stress on the continuity of Cultural Revolution art with what went before, can we use the former's response to a manifest trauma to think about the ways in which artists like Fang Junbi (see plate 5) were reacting to the trauma of dynastic collapse and the incomplete achievement of the Republican project of 'modern China'? This is clearly an area demanding further research, and one potentially able to support an alternative history of Chinese 
art in the twentieth century which is less in thrall to reductive binary oppositions of Chinese and Western, modern and traditional, and even of word and image.

If the artists of China's Republican era faced the issue of how best to write on the picture, and the art of the Maoist era dealt with that of writing in the picture, it is worth concluding by thinking about a rare case of what can only be described as writing ' behind' the picture. On $18^{\text {th }}$ August 1966, as Mao Zedong for the first time addressed the Red Guards in Tiananmen Square, in an event which is now seen as central to the launching of the Cultural Revolution, the painter Zhao Wenliang (b. 1937), who at twenty-nine and hence born in the Republican period was rather too old to be a Red Guard (not to mention his 'bad' class background as the son of a family with Nationalist Party members), decamped to the countryside outside Beijing with two friends. There he began work on an oil sketch (plate 11) which includes the red walls surrounding the early fifteenth-century tomb of the first Ming emperor to reign in Beijing, and the tiles of imperial yellow topping them. Zhao was to form part of the 'No Name Group’ (Wu ming huahui) of painters, working essentially in secret during the following ten years, sharing their art only with each other, and operating below the radar of the party-state's organs of culture. ${ }^{61}$ Some time later (he does not specify exactly when), Zhao inscribed this painting, not on its 
surface, but on the reverse of the paper sheet, with the following words:

After painting this on August 18 1966, the bloodshed and terror of the 'Red August' began. We had to stop painting for forty-five days. On October 2 we took up the brush again. I kept this painting in my painting case for almost ten years. ${ }^{62}$

The gap between the painting and its inscribing decades later is reminiscent of types of inscription seen on premodern painting, practices which reached their apogee on certain works by the Qianlong emperor (r.1736-1795), where repeated reinscription of the surface of the painting turns some of them into works dealing with temporality as much as with the spatiality which is its ostensible and obvious subject. ${ }^{63}$ But then again there are ruptures with past practice, most notably in the inscribing of the reverse of the painted surface rather than its front, which in its swirling materiality of oil paint is very much faithful to its modernist credo of 'truth to materials', even to 'art for art's sake', both equally anathema to official Chinese state artistic policy at the time it was painted. There is a picture, and there is writing, and they relate to each other. But here they do so neither in the way of the premodern colophon, which asserts that 'this is not real, it is a picture', nor in the way of the Maoist metadocument, which asserts that 'this is not 
a picture, it is real'. In the case of Zhao Wenliang's 'August 18' the words and the picture can never be looked at simultaneously, since they are on two sides of the same paper surface. If we look at one, we cannot see the other, though we may remember that it is there. The indeterminacy of the image is balanced by the explicitness of the wording, which is no more afraid than many other Chinese to use the words 'bloodshed and terror'. The wording is personal, and neither it nor the image repeat other words and other images, rather they both partake of the “'free’ discourse exempt from all repetition' that Roland Barthes saw as liberating. Seen by few and read by fewer at the times of painting and writing, '18 August' nevertheless suggests that the options of writing on the painting or writing in the painting may not, in the end have been the Chinese artist's only options, just as the stark choice between (traditional) 'Chinese' or (Western) 'modern' may not be the only options; it suggests further possibilities which have always been grasped by those with the integrity and the imagination to do so.

Notes

The author acknowledges with gratitude the invaluable assistance of the China Academy of Arts, Hangzhou, of Mr Yu Xuhong, Director of the Academy's Gallery, Ms Zhang Suqi and of Dr Zhang Ping in sourcing illustrations for this article. Every effort has been made to contact rights holders, but where this has not proved possible to date, the author and 
publisher will be happy to hear from any copyright holders who wish to get in touch.

${ }^{1}$ W. J. T. Mitchell, Picture Theory, Chicago and London, 1994, 109; Michael Roth, Schrift als Bild, Berlin, 2010.

${ }^{2}$ Zhang Hongxing, 'Re-reading Inscriptions in Chinese Scroll Painting: The Eleventh to the Fourteenth Centuries’, Art History, 28:5, November 2005, 606-25.

${ }^{3}$ Zhang, 'Re-reading Inscriptions’, 607; Craig Clunas, Pictures and Visuality in Early Modern China, London, 1997, 109.

${ }^{4}$ John Hay, “Boundaries and Surfaces of Self and Desire in Yuan Painting', in John Hay, ed., Boundaries in China, London, 1994, 124-70.

${ }^{5}$ This relates to a view much later developed by Jean-François Lyotard, in his consideration of the sign and its relationship to the limits of representation. James Williams, Lyotard: Towards a Postmodern Philosophy, Cambridge, 1998, 21-2. 6 'Notes of a Painter on his Drawing' (1939), in Jack Flam, Matisse on Art, 2nd edn, Berkeley/Los Angeles/London, 1995, 132. My thanks to Alastair Wright for tracing this reference.

${ }^{7}$ Susan Bush and Hsio-yen Shih, Early Chinese Texts on Painting, Cambridge, MA and London, 1985, 224.

${ }^{8}$ E.g. Zheng Wenhui, Shi qing hua yi: Mingdai tihuashi de shihua duiying neihan, Taibei, 1995.

${ }^{9}$ Jonathan Chaves, The Chinese Painter as Poet, New York, 2000; Craig Clunas, 'Reading Wen Zhengming: Metaphor and Chinese Art', Word and Image, 25:1, January-March 2009, 96-102.

${ }^{10}$ Translated in Marsha Weidner, Ellen Johnston Laing, Irving Yucheng Lo, Christina Chu, James Robinson, Views from Jade Terrace: Chinese Women Artists 1300-1912, Indianapolis, 1988, 75-6.

${ }^{11}$ Shane McCausland, 'Copying and Transmitting, Knowledge and Nonsense: From the Great Encyclopaedia to a Book from the Sky', in Nicholas Pearce and 
Jason Steuber eds., Original Intentions: Essays on Production, Reproduction, and Interpretation in the Arts of China, Gainesville, FL, 2012, 236-63.

${ }^{12}$ Wu Hung, 'Reinventing Books in Contemporary Chinese Art', in Making History: Wu Hung on Contemporary Art, Hong Kong, 2008, $65-90$ (p. 66).

${ }^{13}$ Kenneth Pomeranz, The Great Divergence: China, Europe and the Making of the World Economy, Princeton, NJ and Oxford, 2000, 25.

${ }^{14}$ Eric Hayot, The Hypothetical Mandarin: Sympathy, Modernity and Chinese Pain, Oxford, 2009, 185 n.15, citing Haun Saussy, The Problem of a Chinese Aesthetic, Stanford, CA, 1993. The issue is not solely one of the reductionism of western Orientalism, but arguably also of the ‘auto-orientalism’ of highly influential work like Li Zehou, Mei de licheng, Beijing, 1981, English edition translated by Song Lizeng, The Path of Beauty: A Study of Chinese Aesthetics, Hong Kong/Oxford/New York, 1994.

${ }^{15}$ Chen Shizeng, 'Wenrenhua de jiazhi', in Li Yunheng, Zhang Shengjie, Yan Lijun eds, Chen Shizeng hua lun, Beijing, 2008, 161-6; Aida Yuen Wong, Parting the Mists: Discovering Japan and the Rise of National-Style Painting in Modern China, Honolulu, 2006, 63-8.

${ }^{16}$ Craig Clunas, Chinese Painting and its Audiences, The A. W. Mellon Lectures in the Fine Arts, National Gallery of Art, Washington. Bollingen Series XXXV: Volume 61, Princeton and London, 2017, 175-8.

${ }^{17}$ Liu Xin, Bainian Zhongguo youhua tuxiang, Taibei, 2002, 22-3 \& 36-7

${ }^{18}$ Jo-Anne Birnie Danzker, Ken Lum and Zheng Shengtian eds, Shanghai Modern: 1919-1945, Munich, 2004, 183 \& 201.

${ }^{19}$ E.g. Hong Kong Museum of Art, The Art of Xu Beihong, Hong Kong, 1988, plate 4 .

${ }^{20}$ Compare Hong Kong Museum of Art, The Art of Xu Beihong, plate 32 (oil painting) and plate 52 (guohua). On Xu Beihong see most recently Ronald 
Otsuka, Xu Fangfang and Chen Hao, Xu Beihong, Pioneer of Modern Chinese

Painting: Selections from the Beihong Memorial Museum, Denver, 2011.

${ }^{21}$ Danzker et al., Shanghai Modern, 112-7

${ }^{22}$ Aida Yuen Wong, The Other Kang Youwei: Calligrapher, Art Activist and Aesthetic Reformer in Modern China, Leiden and Boston, 2016, 124-35 draws attention to what she terms 'disjunctive portraiture'.

${ }^{23}$ Lu Xuanfei, 'Chen Shizeng “Beijing fengsu tu” zhong de Riben qishi’, Meishushi yanjiu jikan, 28, 2010, 185-266 (pp. 214-5).

${ }^{24}$ On Fang’s biography see Frank Dunand ed., The pavilion of marital harmony:

Chinese painting and calligraphy between tradition and modernity, Geneva, 2002, 21.

${ }^{25}$ The literature on Republican artistic debates is large and growing; key works in English would include: Ralph Croizier, Art and Revolution in Modern China: The Lingnan (Cantonese) School of Painting, 1906-1951, Berkeley/Los

Angeles/London, 1988; Michael Sullivan, Art and Artists of Twentieth-century China, Berkeley, 1996; Kuiyi Shen, 'On the Reform of Chinese Painting in Early Republican China', in Cao Yiqiang and Fan Jingzhong eds., Chinese Painting in the Twentieth Century: Creativity in the Aftermath of Tradition, Hangzhou, 1997, 602-22; John Clark Modern Asian Art, Honolulu, 1998; Julia Andrews, A Century in Crisis: Modernity and Tradition in $20^{\text {th }}$-century Chinese Art, New York, 1998; Birnie Danzker et al., Shanghai Modern; Wong, Parting the Mists; Xiaobing Tang, Origins of the Chinese Avant-Garde: The Modern Woodcut Movement, Berkeley/Los Angeles/London, 2008; John Clark, Modernities of Chinese Art, Leiden, 2010; Lü Peng, A History of Art in 20 th -Century China, Milan, 2010.

${ }^{26}$ David Der-wei Wang, 'In the Name of the Real', in Maxwell K. Hearn and Judith G. Smith eds., Chinese Art: Modern Expressions, New York, 2001, 28-59.

${ }^{27}$ For the salutary example of Shi Lu (1919-1982) see Juliane Noth, 'Confucius and Tolstoy in India: Shi Lu's Paintings of 1970 and the Socialist Culture of 
Maoist-Period China', Art History, November 2016,

http://onlinelibrary.wiley.com/doi/10.1111/1467-8365.12217/epdf [accessed 22

August, 2016], also: Julia F. Andrews, Painters and Politics in the People's

Republic of China 1949-1979, Berkeley/Los Angeles/London, 1994, 307-8;

Shelley Drake Hawks, ‘Summoning Confucius: Inside Shi Lu’s Imagination’ in

Richard King ed., Art in Turmoil: the Chinese Cultural Revolution 1966-1976,

Vancouver BC, 2010, 58-92. On the Yan'an Forum see B.S. McDougall, Mao

Zedong's 'Talks at the Yan'an conference on literature and art', Ann Arbor,

1980; on artistic debate of the early People’s Republic see Julia F. Andrews,

'Traditional Painting in New China: Guohua and the Anti-Rightist Campaign', Journal of Asian Studies 49.3 Autumn 1990, 555-86.

${ }^{28}$ Published in Fan: Xubaizhai Collection of Chinese Painting and Calligraphy, Collection Catalogue, Hong Kong, 1994, 154-5; see also Suk-young Kim, 'From Imperial Concubine to Model Maoist: The Photographic Metamorphosis of Mei Lanfang', Theatre Research International, 31.1, 2006, 37-53.

${ }^{29}$ Andrews, Painters and Politics, 148-161; Chang-tai Hung, 'Oil Paintings and Politics: Weaving a Heroic Tale of the Chinese Communist Revolution’, Comparative Studies in Society and History, 49.4, October 2007, 783-814.

${ }^{30}$ Wang Mingxian and Yan Shanchun, Xin Zhongguo meishu tushi 1966-1976,

Beijing, 2000 is one of the few comprehensive surveys, see also Barbara Mittler, A Continuous Revolution: Making Sense of Cultural Revolution Culture, Cambridge MA, 2012, 257-370, Melissa Chiu and Zheng Shengtian eds., Art and China's Revolution, New York, 2008 and King, ed., Art in Turmoil.

${ }^{31}$ Mittler, Continuous Revolution, 6 \& 10.

${ }^{32}$ For periodization see Frank Dikötter, The Cultural Revolution: A People's

History, 1962-1976, London, 2016.

${ }^{33}$ On the campaign see Merle Goldman, China's Intellectuals: Advise and

Dissent, Cambridge MA, 1981. For a trenchant refusal to allow the designation 
‘Cultural Revolution’ to be applied retrospectively to the entire 1966-76 decade see Michael Bonnin, The Lost Generation: The Rustication of China's Educated Youth (1968-1980), Hong Kong, 2013, xxi-xxii.

${ }^{34}$ W. J. T. Mitchell, What Do Pictures Want?: The Lives and Loves of Images, Chicago and London, 2005, 158.

${ }^{35}$ Francesca Dal Lago, ‘Activating Images: The Ideological Use of Metapictures and Visualized Metatexts in the Iconography of the Cultural Revolution', Modern Chinese Literature and Culture, 21.2, Fall 2009, 167-97.

${ }^{36}$ Quanguo meishu zuopin zhanlan bangongshi ed., Quanguo nianhua, shaonian ertong meishu zuopin zhanlan: Nianhua xuanji 1975, Beijing, 1977, 90. On Nan Yunsheng see http://baike.baidu.com/view/1076236.htm on Wan Guixiang, specifically identified in the text as a woman artist see http://baike.baidu.com/view/1700951.htm [accessed 6 January 2015].

${ }^{37}$ http://baike.baidu.com/view/6015997.htm [accessed 8 January 2015].

${ }^{38}$ http://baike.baidu.com/view/2786907.htm [accessed 8 January 2015].

${ }^{39}$ Mittler, Continuous Revolution, 217-24.

${ }^{40}$ James A. Flath, The Cult of Happiness: Nianhua, Art, and History in Rural North China, Vancouver 2004, especially 96-125, 'Rural Print and the Cosmopolitan Mystique’.

${ }^{41}$ Chang-tai Hung, 'Repainting China: New Year Prints (Nianhua) and Peasant Resistance in the Early Years of the People’s Republic', Comparative Studies in Society and History, 42.4, December 2000, 770-810.

${ }^{42}$ Chiu and Zheng, Art and China's Revolution, 118-32.

${ }^{43}$ Nianhua xuanji 1975, 95. On Pan Dingding see http://artist.artxun.com/35295pandingding/ [accessed 6 January 2015].

${ }^{44}$ Paul Clark, 'Film-Making in China: From the Cultural Revolution to 1981', China Quarterly, 94, June 1983, 304-22 (p. 310). 
45 The Chinese title is Biye huibao, reproduced in Nianhua xuanji 1975, 70.

Information is scarce on the artist Huang $\mathrm{Gu}$, but for the probable artist of this work, see http://www.zhfgwh.com/zt/artshow/huanggu.html [accessed 6 January 2015].

${ }^{46}$ Dal Lago, ‘Activating Images’, 168.

${ }^{47}$ Pedro Pak-Tao Ng, 'Open-Door Education in Chinese Communes: Rationale, Problems, and Recent Changes’, Modern China, 6.3, July 1980, 327-56.

${ }^{48}$ The fullest account in English of the policy is Bonnin, The Lost Generation, see especially pp. 235-336.

${ }^{49}$ See for example the collection of photographs and reminiscences on the ‘educated youth tribe’, Zhu Zhenghui and Jin Guangyao, Zhiqing buluo, Shanghai, 2004, and the many works of fiction cited in Bonnin, Lost Generation. ${ }^{50}$ Michael Schoenhals, Doing Things with Words in Chinese Politics: Five Studies, Berkeley CA, 1992. A very useful glossary of Cultural Revolution terminology is provided in Helen Wang, Chairman Mao Badges: Symbols and Slogans of the Cultural Revolution, London, 2008, available online at http://www.britishmuseum.org/pdf/5\%20-\%20HW-\%20Glossary\%20edJt\%20ed-HW.pdf [accessed 6 January 2015].

${ }^{51}$ Igor Golomstok, Totalitarian Art: in the Soviet Union, the Third Reich, Fascist Italy and the People's Republic of China, translated from the Russian by Robert Chandler London, 1990, xii-xiii.

${ }^{52}$ Roland Barthes, 'The Reality Effect', in The Rustle of Language, translated by Richard Howard, Oxford, 1986, 141-8.

${ }^{53}$ The instructive case of the images on postage stamps, and the mechanisms for approving new designs, has been studied in Yu-chin Huang, 'National Identity and Ideology in the Design of Postage Stamps of China and Taiwan, 1949-1979', PhD thesis, School of Oriental and African Studies, London, 2007. 
${ }^{54}$ Mittler, Continuous Revolution, 10, citing Rainer Gries and Wolfgang Schmale eds, Kultur der Propaganda, Bochum, 2005.

${ }^{55}$ Roland Barthes, Travels in China, edited, annotated and with a foreword by Anne Herschberg Pierrot, translated by Andrew Brown, Cambridge, 2012, 188.

${ }^{56}$ Barthes, Travels in China, p. 195.

${ }^{57}$ As in Mittler, Continuous Revolution, 269

${ }^{58}$ Hal Foster, The Return of the Real: The Avant-Garde at the End of the Century, Cambridge MA and London, 1996, 131-2.

${ }^{59}$ Foster, Return of the Real, 141-2.

${ }^{60}$ Mittler, Continuous Revolution, 272.

${ }^{61}$ The name was coined in 1979, on the occasion of a first public exhibition of their work. Juliane Noth, 'Landscapes of Exclusion: the No Name Group and the Multiple Modernities of Chinese Art around 1979’, in Birgit Hopfener, Franziska Koch, Jeong-hee Lee Kalisch and Juliane Noth eds, Negotiating Difference: Contemporary Chinese Art in the Global Context, Weimar, 2012, 49-62.

${ }^{62}$ Noth, 'Landscapes of Exclusion', 51-2 where the inscription is dated to 2005.

A slightly different translation (for example with singular instead of plural pronouns) appears in Gao Minglu, 'No Name Group: Contemporary Recluses the Bo Yi's and Shu Qi’s of the Cultural Revolution', in Chiu and Zheng eds., Art and China's Revolution, 178-185 (p. 179).

${ }^{63}$ Clunas, Chinese Painting and its Audiences, 106-9 